\title{
DNA Concentrations in the Human Cerebellum. Computation from Kinetics of Deoxyribose Extraction in Hot Acid
}

\author{
DANIEL N. SLATKIN ${ }^{a}$ and SØREN LØVTRUP ${ }^{b}$
}

a Medical Department, Brookhaven National Laboratory, Upton, New York, U.S.A. and

${ }^{b}$ Department of Zoophysiology, University of Umeå, S-Umeå, Sweden

DNA can be measured in mammalian tissues by extracting deoxyribose from unfixed, lyophilized tissue specimens with $0.5 \mathrm{~N}$ perchloric acid at $90{ }^{\circ} \mathrm{C}$. Deoxyribose concentrations in the extract are determined photometrically by reaction with diphenylamine. Inevitably, some deoxyribose is destroyed during exposure to the hot acid. A computer program has been written which corrects photometric absorbance data for such loss of deoxyribose. When extrapolated to infinite duration of extraction, the corrected absorbances yield a measure of the DNA content of the specimen.

This method was used to estimate DNA concentrations in human cerebellar cortex and white matter. The results are discussed in relation to stable carbon isotope ratios of human cerebellar DNA.

Several photometric methods for estimating tissue DNA are based on measurements of extractable deoxyribose, because almost all deoxyribose in animal tissues exists as the pentose moiety of DNA. ${ }^{1}$ Deoxyribose can be almost completely extracted from mammalian tissues within a few hours using $0.5 \mathrm{~N}$ perchloric acid at $90^{\circ} \mathrm{C}$. To compensate for the concomitant partial destruction of deoxyribose during its exposure to hot acid, Løvtrup and Roos devised a reiterative graphical procedure (LRP) for extrapolating the corrected absorbance, $A_{\mathrm{o}}^{*}$, from the sequence of absorbances observed after the reaction of diphenylamine with sequential aliquots of the extract. ${ }^{2-4}$ They found that $A_{\mathrm{o}}^{*}$, the corrected absorbance which would have been observed after prolonged extraction had there been no concomitant destruction of deoxyribose, correlated well with independent microbiological assays of tissue DNA.

Although other techniques are available for determining DNA in tissue, photometric methods based on the extraction of deoxyribose from tissue powder by hot acid, ${ }^{5-7}$ the so-called Schneider procedure, are convenient and are used widely. It has been found that DNA concentrations measured by such extractions vary in accuracy with the type of tissue being analyzed and with the physiological state of cells in a specimen, apparently due to differences in the extractability of deoxyribose or to variable rates of deoxyribose destruction by hot acid. ${ }^{8-11}$ In 1966, Munro and Fleck ${ }^{12}$ suggested that automated analysis may restore the attractiveness of the Schneider procedure in spite of inherent errors in extraction. The computation method described in this communication fulfills Munro and Fleck's criterion of full automation of data analysis, while taking into account not only the kinetics of deoxyribose extraction and destruction but also the presence of acid-resistant interfering substances in the extract. Although the principle of the calculation is straightforward, a small computer is required to carry it out.

\section{THEORY}

In the LRP each absorbance was corrected by adding the estimated loss of absorbance attributable to prior destruction of deoxyribose in the hot acid extract. Program CORABS (Tables 1 and 2) obtains the corrected absorbance, $A_{\mathrm{o}}^{*}$, using a 
similar technique. Correction is discontinuous, as in the LRP, until the time of maximum absorbance, $t_{\mathrm{m}}$. Thereafter, correction is continuous by integration of a function which fits absorbance values in the range $t \geq t_{\mathrm{m}}$, where $t$ is the duration of extraction. Suppose

$$
A(t)=K+A_{\mathrm{u}}(t)
$$

where $A(t)$ is the absorbance observed after $t$ min of extraction, $A_{\mathrm{u}}(t)$ is the portion of observed absorbance attributable to deoxyribose, and $K$ is the absorbance attributable to acid-resistant interfering substances. Assume that, for $t>t_{0}$, extraction and destruction kinetics are exponential. That is, if

$t^{\prime}=t-t_{\mathrm{o}}$

$\mathrm{d} A_{\mathrm{u}}\left(t^{\prime}\right) / \mathrm{d} t^{\prime}=k_{\mathrm{u}} D \mathrm{e}^{-k_{\mathrm{u}} t^{\prime}}-k_{\mathrm{e}} A_{\mathrm{u}}\left(t^{\prime}\right)$

where $k_{\mathrm{u}}$ and $k_{\mathrm{a}}$ are the apparent time constants for extraction and destruction of deoxyribose, respectively, and $D$ is the tissue deoxyribose pool at $t^{\prime}=0$. Such kinetic behavior implies

$$
A\left(t^{\prime}\right)=K+S_{1} \mathrm{e}^{-k_{e} t^{\prime}}-S_{2} \mathrm{e}^{-k_{\mathrm{u}} t^{\prime}}
$$

where $S_{1}$ and $S_{2}$ are constants of integration.

Actually, absorbance values are found to fit similar equations of the form

$$
A\left(t-t_{\mathrm{o}}\right)=V+S \mathrm{e}^{-\mathrm{k}_{\mathrm{e}}\left(t-t_{0}\right)}-S \mathrm{e}^{-\mathrm{k}_{\mathrm{u}}\left(t-t_{\mathrm{o}}\right)}
$$

where $t \geq t_{\mathrm{m}}$ and $V, S, k_{\mathrm{u}}, k_{\mathrm{e}}$ and $t_{\mathrm{o}}$ are empirical constants. Thus, if $A_{\mathrm{m}}^{*}$ is the absorbance at $t=t_{\mathrm{m}}$ corrected by the LRP for deoxyribose loss prior to $t_{\mathrm{m}}$,

$A_{\mathrm{o}}^{*}=A_{\mathrm{m}}^{*}+\int_{t_{\mathrm{m}}^{\prime}}^{\infty}\left(A\left(t^{\prime}\right)-V\right) \cdot k_{\mathrm{e}} \cdot \mathrm{d} t^{\prime}$

where

$t_{\mathrm{m}}^{\prime}=t_{\mathrm{m}}-t_{\mathrm{o}}$

These equations yield $A_{\mathrm{o}}^{*}$, the absorbance corrected for loss of deoxyribose and extrapolated to infinite duration of extraction:

$A_{\mathrm{o}}^{*}=A_{\mathrm{m}}^{*}+k_{\mathrm{e}} \cdot S \cdot\left(e^{-k_{\mathrm{e}} t_{\mathrm{m}}^{\prime}} / k_{\mathrm{e}}-\mathrm{e}^{-k_{\mathrm{u}} t_{\mathrm{m}}^{\prime}} / k_{\mathrm{u}}\right)$
Eqn. (5) is similar to the following equation of the LRP.

$A(t)=A_{\infty}+\left(A_{\mathrm{o}}-A_{\infty}\right) \times 10^{-k t}$

$V$ is the analogue of $A_{\infty}$ and $S$ is the analogue of $\left(A_{\mathrm{o}}-A_{\infty}\right)$. The analogue of $k$ is $k_{\mathrm{e}}$ where

$k_{\mathrm{e}}=k(\ln 10)$

Since eqn. (9) has no parameter analogous to $k_{\mathrm{u}}$, it cannot fit absorbances at or near the maximum absorbance.

\section{COMPUTER PROGRAM}

Program CORABS determines empirical values of $t_{\mathrm{o}}, V, S, k_{\mathrm{e}}$ and $k_{\mathrm{u}}$ which minimize the deviation of observed absorbance values from isochronous absorbance values on the fitted curve (eqn. (5)). It is postulated that the probability of relating absorbance values with deoxyribose concentrations decreases with time exponentially, with the same time constant as that of deoxyribose destruction. Thus, in line 150 of the curve-fitting algorithm of CORABS, each absorbance point, $A(t)$, is assigned the statistical weight $\mathrm{e}^{-k_{e} t} \cdot|A(t)-K|$.

The calculation of $A_{\mathrm{m}}^{*}$ in eqn. (8) is based on the LRP. In the LRP, the average absorbance between the start of extraction and $t_{1}$, the time of the first observed absorbance, is estimated as $0.75 A\left(t_{1}\right)$ if $t_{1}=t_{\mathrm{m}}$ and as $0.50 A\left(t_{1}\right)$ if $t_{1} \neq t_{\mathrm{m}}$. A quantitative basis for such approximations was developed by observing that the initial rapid increase in absorbance is roughly exponential. Then, if

$x=\left(A\left(t_{1}\right)-K\right) /\left(A\left(t_{\mathrm{m}}\right)-K\right)$

it can be shown that the ratio to $A\left(t_{1}\right)-K$ of the average net absorbance prior to $t_{1}$ is

$y \simeq x^{-1}+(\ln (1-x))^{-1}$

In the range $0.90<x<0.99, y$ varies from 0.68 to 0.79 , and averages 0.72 , the factor used in line 220 of CORABS for $t_{1}=t_{\mathrm{m}}$. This is close to the factor 0.75 used in the LRP. If $t_{1} \neq t_{\mathrm{m}}$, eqns. (11) and (12) are used to estimate the average absorbance in the range $0<t<t_{1}$. In CORABS, 
absorbances at or below $A\left(t_{\mathrm{m}}\right) / 5$ are automatically neglected in the calculation of $A_{\mathrm{o}}^{*}$. This minimizes errors in $A_{\mathrm{o}}^{*}$ which otherwise could be attributed to acid-resistant interfering substances extracted slowly from tissue powder.

The curve-fitting algorithm of CORABS makes use of the following relationships among $k_{\mathrm{u}}, k_{\mathrm{e}}, t_{\mathrm{m}}$, and $t_{\mathrm{o}}$. If

$f=\left(t_{\mathrm{m}}-t_{\mathrm{o}}\right) / w$

where $w$ min is the time interval between aliquot samples of the extract, and if

$g=k_{\mathrm{u}} / k_{\mathrm{e}}$

it may be shown from the first derivative of eqn.

(5) that

$\ln g=w f k_{\mathrm{e}}(g-1)$

The solution of eqn. (15) is $g=\lim [1+\ln (1+\ln (1+\ln \ldots$

$\left.\left.\left.\left(1+\ln \left(1+\ln g \mathrm{o}\left(w f k_{\mathrm{e}}\right)\right)\right) \ldots\right)\right)\right]$

where $g_{0}$ is any real number greater than one. Eqn. (16) is used in line 120 of CORABS. Eqns. (13) through (16) are used in CORABS to calculate provisional values of $k_{\mathrm{u}}$ from tentative values of $t_{\mathrm{o}}$ and $k_{\mathrm{e}}$, as indicated by the first command of line 130 in CORABS. Provisional values of $k_{\mathrm{e}}$ are calculated from absorbance values at $\gg t_{\mathrm{m}}$ using Guggenheim's algorithm, ${ }^{13}$ as in the LRP.

The particular version of program CORABS displayed in Table 1 is written in a BASIC computer language specified for the Casio FX702P pocket computer. ${ }^{14}$ In addition to standard BASIC functions, the following special statistical functions of this portable $(186 \mathrm{~g})$ minicomputer are used in CORABS.

STAT $x ; y$ assigns the statistical weight $y$ to the number $x$ in a series of numbers during calculation of the standard deviation.

Table 1. List of program CORABS.

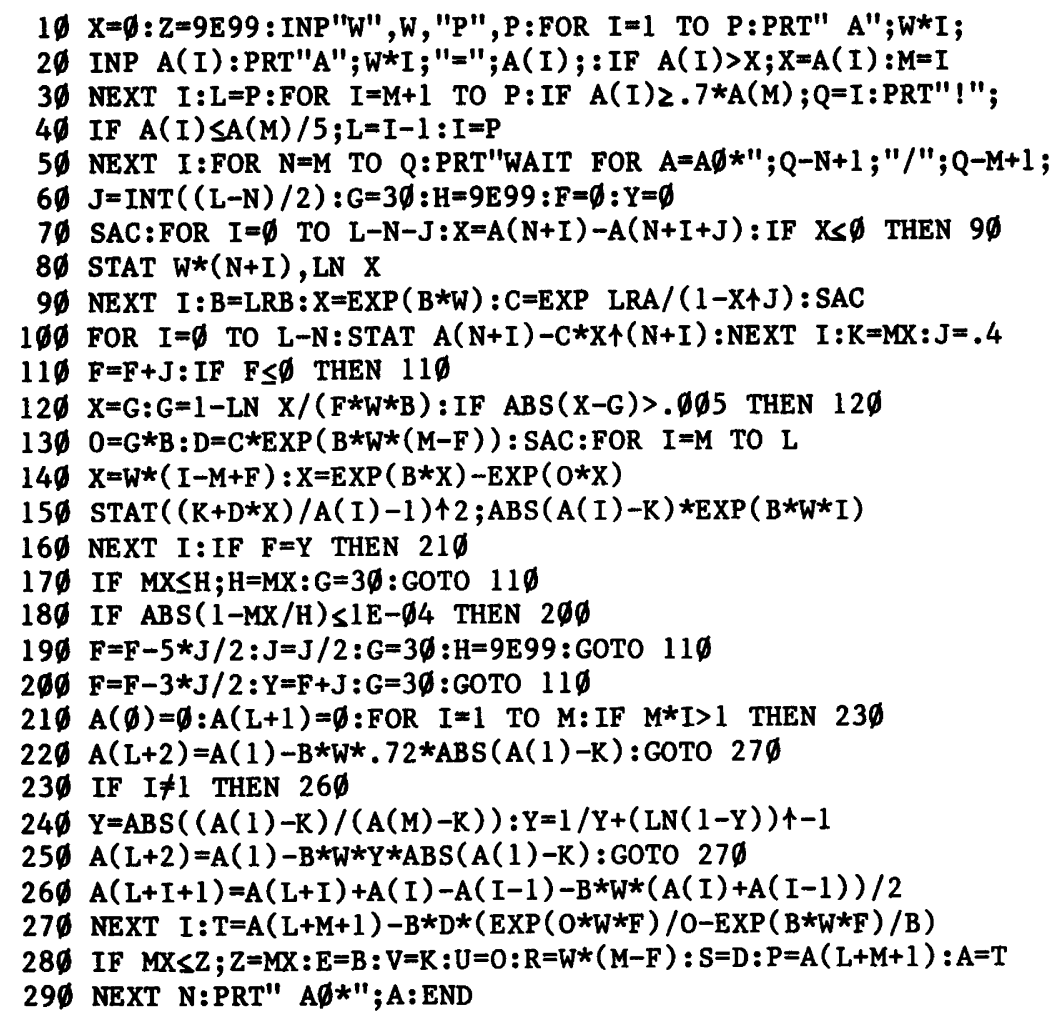


$M X$ calculates the weighted arithmetic mean of data entered during standard deviation analysis.

STAT $x, y ; z$ assigns the statistical weight $z$ to the point $(x, y)$ in a series of points during calculation of the regression line through those points.

$L R A$ and $L R B$ calculate the $y$-intercept and the slope of the regression line, respectively.

$S A C$ clears the statistical processing registers.

The commands, STAT, MX, LRA, LRB, and SAC can be replaced by subroutines if CORABS is modified for a computer which does not happen to use such statistical functions directly. When running program CORABS, the time interval in minutes between removal of aliquots

Table 2. Parameters of program CORABS.

A Computed value of $A_{\mathrm{o}}^{*}$, eqn. (8)

B Provisional values of $-k_{\mathrm{e}}$

C Intermediate parameter, analogous to $A_{\mathrm{o}}-A_{\infty}$ of the original Løvtrup-Roos procedure

D Provisional values of $S$

E Computed value of $-k_{\mathrm{e}}$

F Intermediate parameter $f$, eqn. (13)

G Intermediate parameter $g$, eqns. (14)-(16)

$\mathrm{H}$ Intermediate variable

I Integral variable

J Intermediate parameter; $\mathrm{W}^{*} \mathrm{~J}$ corresponds to $\tau$ of Guggenheim's algorithm, Ref. 13

K Provisional values of $V$

L Array integer for the last observed absorbance greater than $A\left(t_{\mathrm{m}}\right) / 5$

$M$ Array integer for the maximum observed absorbance, $A\left(t_{\mathrm{m}}\right)$

$\mathrm{N}$ Integral variable

O Provisional values of $-k_{\mathrm{u}}$

P Number of observed absorbance points; finally, computed value of $A_{\mathrm{m}}^{*}$

Q Array integer for the last observed absorbance greater than or equal to $0.7 \mathrm{~A}\left(t_{\mathrm{m}}\right)$

$\mathrm{R}$ Computed value of $t_{\mathrm{o}}$, eqn. (5)

$S$ Computed value of $S$, eqn. (5)

T Provisional values of $A_{\mathrm{o}}^{*}$

$\mathrm{U}$ Computed value of $-k_{\mathrm{u}}$

$\mathrm{V}$ Computed value of $V$, eqn. (5)

W Constant time interval between aliquots of acid extract, minutes

$\mathrm{X}$ Intermediate variable

Y Intermediate variable

$\mathrm{Z}$ Weighted mean square fractional deviation of absorbance points from the fitted curve, eqn. (5) of the extract and the total number of such aliquots are entered and stored in registers $\mathrm{W}$ and $\mathrm{P}$, respectively. The $600 \mathrm{~nm}$ absorbances determined from these aliquots are entered sequentially and stored in the array $\mathrm{A}(1), \mathrm{A}(2), \ldots, \mathrm{A}(\mathrm{P})$. These absorbance values correspond to $W$, $2 \mathrm{~W}, \ldots$, and $\mathrm{PW}$ minutes of extraction, respectively. $A_{\mathrm{o}}^{*}$ is then computed, stored in register $\mathrm{A}$, and displayed automatically. Registers $B$ through $\mathrm{Z}$ are used for other parameters of CORABS, as shown in Table 2.

The following separate three-command program can be used to generate points on the fitted curve, eqn. (5).

\section{INP "T", T:PRT V+S* $\left(\operatorname{EXP}\left(E^{*}(T-R)\right)-\right.$ $\left.\operatorname{EXP}\left(\mathrm{U}^{*}(\mathrm{~T}-\mathrm{R})\right)\right) ;: \mathrm{GOTO} 1$}

Examples of fitted curves together with the absorbance points from which they are derived are shown in Fig. 1, where absorbance data are from case No. 1 .

\section{EXPERIMENTAL}

Lateral lobes of four normal human cerebella were removed post-mortem, then frozen at $-70{ }^{\circ} \mathrm{C}$ pending DNA analysis. Information concerning the autopsies is shown in Table 5. Each cerebellum was normal, and the decedents showed no evidence of primary neurological disease. Cadavers were refrigerated prior to the autopsy.

Each cerebellar specimen was divided into white matter and cortical portions by macroscopic dissection, and the portions were lyophilized separately. Weighed portions of these tissue powders and known quantities of calf thymus DNA were treated concurrently with $5 \%$ perchloric acid at $90^{\circ} \mathrm{C}$, as described previously. ${ }^{2-4}$ Aliquots $(1 \mathrm{ml})$ of the extracts were removed every $5 \mathrm{~min}$. The aliquots were treated with diphenylamine, and the resulting $600 \mathrm{~nm}$ absorbance readings were tabulated for entry into the array $\mathbf{A}(1), \mathbf{A}(2), \ldots, \mathbf{A}(\mathrm{P})$. The results of processing these data with program CORABS are shown in Tables 3 and 4 .

\section{DISCUSSION}

Only a few investigators ${ }^{15,16}$ have reported using the Løvtrup-Roos correction procedure, presumably because the original procedure is difficult. Since the computation of $A_{\mathrm{o}}^{*}$ is now 


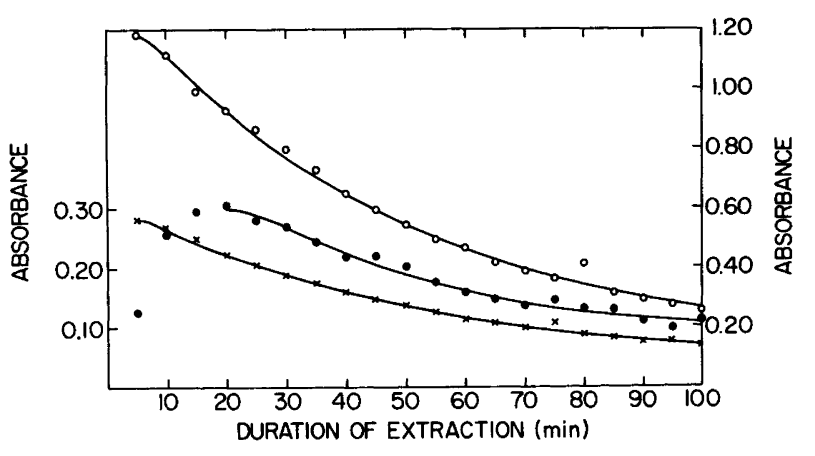

Fig. 1. Absorbance data and fitted curves for case No. 1. The upper curve (open circles, cerebellar cortex) corresponds to the ordinate on the right (scale: zero to 1.20). The middle (closed circles, cerebellar white matter) and lower (small x's, DNA control) curves correspond to the ordinate on the left (scale: zero to 0.30).

automated, the Løvtrup-Roos correction should be more easily applied.

The computer program presented here (Tables 1 and 2) is based on the original Løvtrup-Roos procedure (LRP). It uses an algorithm which fits an empirical kinetic equation to absorbance values beginning at the time of extraction which yields maximum absorbance. In the LRP, $A_{\mathrm{o}}^{*}$ is obtained by extrapolation from absorbances observed during the first few hours of extraction. The program presented here uses a formula to calculate $A_{\mathrm{o}}^{*}$ by extrapolation to infinite duration of extraction with continuous compensation for destruction of deoxyribose.
Tissues analyzed were post-mortem specimens of human cerebellar cortex and cerebellar white matter. It can be calculated from the results of analyses listed in Tables 3 and 4 that average concentrations of DNA in cerebellar cortex and white matter are $0.72 \pm 0.02 \mu \mathrm{g}$ per mg dry tissue and $0.05 \pm 0.01 \mu \mathrm{g}$ DNA per $\mathrm{mg}$ dry tissue, respectively. It was also found that the average concentration of DNA in the macroscopically dissectable human cerebellar leptomeninges and blood vessels is less than $0.20 \mu \mathrm{g}$ per $\mathrm{mg}$ dry weight. Comparison of Tables 4 and 5 shows no correlation between age, time interval between death and autopsy, and cerebellar DNA concen-

Table 3. Results obtained using the program CORABS.

\begin{tabular}{|c|c|c|c|c|c|c|c|}
\hline $\begin{array}{l}\text { Case } \\
\text { No. }\end{array}$ & Specimen & $A_{\mathrm{m}}^{*}$ & $S$ & $\boldsymbol{V}$ & $t_{\mathrm{o}}$ & $k_{\mathrm{u}}$ & $k_{\mathrm{e}} \times 10^{2}$ \\
\hline 1 & Cerebellar cortex & 1.260 & 1.285 & 0.108 & -1.72 & 0.4921 & 2.0736 \\
\hline 1 & Cerebellar white matter & 0.419 & 0.354 & 0.081 & 8.61 & 0.1990 & 2.8571 \\
\hline 1 & Standard DNA & 0.300 & 0.287 & 0.032 & -0.28 & 0.6879 & 2.0231 \\
\hline 2 & Cerebellar cortex & 1.237 & 1.045 & 0.098 & 6.70 & 1.2884 & 1.9652 \\
\hline 2 & Cerebellar white matter & 0.510 & 0.625 & 0.055 & -2.84 & 0.1786 & 2.4805 \\
\hline 2 & Standard DNA & 0.301 & 0.283 & 0.032 & 0.38 & 0.8203 & 2.0418 \\
\hline 3 & Cerebellar cortex & 1.335 & 0.751 & 0.149 & 20.00 & 4137.7 & 2.2501 \\
\hline 3 & Cerebellar white matter & 0.377 & 0.292 & 0.059 & 9.98 & 0.7135 & 2.2269 \\
\hline 3 & Standard DNA & 0.312 & 0.365 & 0.044 & -7.32 & 0.2015 & 2.2103 \\
\hline 4 & Cerebellar cortex & 1.109 & 1.649 & -0.390 & -0.59 & 0.3318 & 1.1099 \\
\hline 4 & Cerebellar white matter & 0.419 & 0.366 & 0.005 & 14.61 & 0.6162 & 2.5520 \\
\hline 4 & Standard DNA & 0.320 & 0.263 & 0.032 & 5.00 & 8808.5 & 2.1936 \\
\hline
\end{tabular}

Acta Chem. Scand. B 37 (1983) No. 4 
Table 4. Results obtained using the program CORABS.

\begin{tabular}{lllll}
\hline $\begin{array}{l}\text { Case } \\
\text { No. }\end{array}$ & Specimen & $\begin{array}{l}\text { Dry } \\
\text { weight }\end{array}$ & $\begin{array}{l}\text { Corrected } \\
\text { absorbance } \\
A_{\mathrm{o}}^{*}\end{array}$ & $\begin{array}{l}\text { DNA } \\
\text { concentration } \\
\mu \mathrm{g} / \mathrm{mg} \text { dry tissue }\end{array}$ \\
\hline 1 & Cerebeller cortex & $209.8 \mathrm{mg}$ & 2.376 & 0.702 \\
1 & Cerebellar white matter & $895.2 \mathrm{mg}$ & 0.669 & 0.046 \\
1 & Standard DNA & $34.6 \mu \mathrm{g}$ & 0.558 & - \\
2 & Cerebellar cortex & $185.0 \mathrm{mg}$ & 2.216 & 0.741 \\
2 & Cerebellar white matter & $904.8 \mathrm{mg}$ & 0.955 & 0.065 \\
2 & Standard DNA & $34.6 \mu \mathrm{g}$ & 0.559 & - \\
3 & Cerebellar cortex & $170.9 \mathrm{mg}$ & 2.086 & 0.719 \\
3 & Cerebellar white matter & $929.5 \mathrm{mg}$ & 0.638 & 0.040 \\
3 & Standard DNA & $34.6 \mu \mathrm{g}$ & 0.587 & - \\
4 & Cerebellar cortex & $210.7 \mathrm{mg}$ & 2.574 & 0.725 \\
4 & Cerebellar white matter & $914.7 \mathrm{mg}$ & 0.737 & 0.048 \\
4 & Standard DNA & $34.6 \mu \mathrm{g}$ & 0.583 & - \\
\hline
\end{tabular}

Table 5. Post-mortem diagnoses.

\begin{tabular}{|c|c|c|c|}
\hline $\begin{array}{l}\text { Case } \\
\text { No. }\end{array}$ & $\begin{array}{l}\text { Age, } \\
\text { sex }\end{array}$ & $\begin{array}{l}\text { Post-mortem } \\
\text { interval } \\
\text { to autopsy }\end{array}$ & Post-mortem diagnoses ${ }^{a}$ \\
\hline 1 & $64 \mathrm{yr}$, male & $<10 \mathrm{hr}$ & $\begin{array}{l}\text { Anaplastic carcinoma of the urinary bladder with local and } \\
\text { systemic metastases. Microscopic metastases in the cerebral dura } \\
\text { and the superior sagittal sinus; brain otherwise normal. Left } \\
\text { hydronephrosis. Recent peptic ulcer of the duodenum. }\end{array}$ \\
\hline 2 & $60 \mathrm{yr}$, male & $17 \mathrm{hr}$ & $\begin{array}{l}\text { Severe panacinar emphysema. Severe right ventricular } \\
\text { hypertrophy. Ascites, peripheral edema, bilateral hydrothorax } \\
\text { and pericardial effusion. Fibrinous pericarditis. Chronic passive } \\
\text { congestion of the liver. Multiple organizing pulmonary arterial } \\
\text { thrombi, probably embolic. Tracheostomy. Large sacral decubitis } \\
\text { ulcer. Small left parietal meningioma and two small, organized } \\
\text { cerebral infarcts, both asymptomatic; brain otherwise normal. }\end{array}$ \\
\hline 3 & $73 \mathrm{yr}$, male & $8 \mathrm{hr}$ & $\begin{array}{l}\text { Squamous cell carcinoma of the lung with local and systemic } \\
\text { metastases. Severe coronary artery atherosclerosis with left } \\
\text { ventricular myocardial scarring and hypertrophy. Acute purulent } \\
\text { bronchopneumonia. Brain normal. }\end{array}$ \\
\hline 4 & $62 \mathrm{yr}$, male & $27 \mathrm{hr}$ & $\begin{array}{l}\text { Squamous cell carcinoma of the esophagus with local and systemic } \\
\text { metastases. Esophageal perforation with focal subacute } \\
\text { mediastinitis. Two small carcinoid tumors of the ileum, } \\
\text { asymptomatic. Acute bronchopneumonia and pulmonary edema. } \\
\text { Brain normal. }\end{array}$ \\
\hline
\end{tabular}

${ }^{a}$ D. N. Slatkin and N. Peress. 
trations.

It has been estimated that the convoluted cerebellar cortex occupies $90 \%$ of the volume of the cerebellum. ${ }^{17}$ Assuming conservatively that not more than $5 \%$ of the cerebellum is occupied by leptomeninges and blood vessels, it is inferred that the non-vascular moiety of the human cerebeller cortex constitutes about $85 \%$ of the cerebellum as a whole. Since $95 \%$ of cerebellar cortical nuclei are in the granular layer of the cortex ${ }^{18}$ and since, in the mammal, over $99 \%$ of granular layer nuclei are neuronal, ${ }^{19}$ it follows that approximately $94 \%$ of all cerebellar cortical nuclei are neuronal. Using the values of DNA concentrations presented here, it is calculated that $92 \%$ of whole cerebellar DNA is situated in neurons of the cerebellar cortex. These calculations are in accord with observations on nuclear fractions of whole cerebellar homogenates from dogs and rats, which show that about $90 \%$ of cerebellar nuclei are neuronal. ${ }^{20,21}$

These measurements of cerebellar DNA lend support to the postulate that there is significant turnover of cerebellar neuronal DNA during the human lifetime. ${ }^{22}$ That postulate is based on stable carbon isotope ratio measurements on the carbon moiety of DNA isolated from unfractionated homogenates of human cerebellar tissue from which only minor portions of the cerebellar white matter and leptomeninges had been removed prior to homogenization for DNA extraction. The foregoing calculations indicate that 90-92 \% of such carbon is derived from cerebellar neuronal DNA. Human tissue ${ }^{13} \mathrm{C} /{ }^{12} \mathrm{C}$ ratios are significantly lower in Europeans than in Americans. ${ }^{23}$ Thus, the finding that ${ }^{13} \mathrm{C} /{ }^{12} \mathrm{C}$ ratios in whole cerebellar DNA from European-born Americans tend to approach ratios which are typical of American tissues is interpreted as evidence that a substantial proportion of neuronal DNA in the cerebellum may undergo slow turnover during adult life.

Acknowledgements. The authors thank Dr. N. Peress for neuropathological examinations, Mrs. Peg Micca and Mrs. Mary Wigger for skilled technical and secretarial assistance, and Drs. S. L. Commerford, H. Løvtrup-Rein, E. A. Popenoe, J. S. Robertson and L. Sokoloff for helpful comments. This work was supported in part by the U.S. Department of Energy.

\section{REFERENCES}

1. Munro, H. N. and Fleck, A. Methods Biochem. Anal. 14 (1966) 113.

2. Løvtrup, S. and Roos, K. Biochim. Biophys. Acta 53 (1961) 1.

3. Løvtrup, S. Acta Biochim. Pol. 9 (1962) 411.

4. Løvtrup, S. and Roos, K. Biochim. Biophys. Acta 68 (1963) 425.

5. Burton, K. Methods Enzymol. 12 (1968) 163.

6. Webb, J. M. and Levy, H. B. J. Biol. Chem. 213 (1955) 107.

7. Ceriotti, G. J. Biol. Chem. 198 (1952) 297.

8. Holm, B. Biochim. Biophys. Acta 119 (1966) 647.

9. Barkowski, T. and Sikorska, K. Acta Biochim. Pol. 11 (1964) 451.

10. Santen, R. J. and Agranoff, B. W. Biochim. Biophys. Acta 72 (1963) 251.

11. Hutchinson, W. C., Downie, E. D. and Munro, H. N. Biochim. Biophys. Acta 55 (1962) 561.

12. Munro, H. N. and Fleck, A. Analyst 91 (1966) 78.

13. Guggenheim, E. A. Philos. Mag. Ser. 7, 2 (1926) 538.

14. Casio Inc., 15, Gardner Road, Fairfield, New Jersey 07006, U.S.A.

15. Martinsson, A., Sunzel, H. and Hood, B. Acta Med. Scand. 173 (1963) 745.

16. Baldwin, R. L. and Milligan, L. P. J. Biol. Chem. 241 (1966) 2058.

17. Smolyaninov, V. V. In Gelfand, I. M. et al., Eds., Models of the Struuctural-Functional Organization of Certain Biological Systems, Moscow 1966; Engl. transl. Beard, C. R., MIT Press, Cambridge, Massachusets 1971, pp. 252-325.

18. Blinkov, S. M. and Glezer, I. I. The Human Brain in Figures and Tables, Basic Books, New York 1968.

19. Palkovits, M., Magyar, P. and Szentagothai, J. Brain Res. 32 (1971) 15.

20. Wheeler, K. T. and Lett, J. T. Radiat. Res. 52 (1972) 59.

21. Kuenzle, C. C., Knüsel, A. and Schümperli, D. Methods Cell Biol. 15 (1977) 89.

22. Slatkin, D. N., Irsa, A. P. and Friedman, L. In Klein, E. R. and Klein, P. D., Eds., Stable Isotopes, Academic, New York 1979, p. 239.

23. Gaffney, J. S., Irsa, A. P., Friedman, L. and Slatkin, D. N. Biomed. Mass Spectrom. 5 (1978) 495.

Received July 16, 1982. 